\title{
Educación Secundaria: paralelismos entre la Institución Libre de Enseñanza y el nuevo proyecto de ley de educación en España
}

\author{
Secondary Education: parallels between the Institución Libre de \\ Enseñanza and the new bill of education in Spain
}

\section{José Patricio Gutiérrez Palomino ${ }^{1}$}

\section{Resumen/Resumo}

La Institución Libre de Enseñanza quiso redefinir la razón de ser de la segunda enseñanza. Con la llegada de la guerra civil desaparece la Institución y, con ella, todas las innovaciones pedagógicas que se implementaron. La reinstauración de la democracia trae consigo la aprobación de sucesivas leyes educativas que tratan de adaptar el sistema educativo español a cada situación social concreta. El propósito de este ensayo radica en contribuir a definir el ser de la segunda enseñanza en el ámbito educativo español, apoyándonos en los principios pedagógicos que guiaron la labor educativa de la Institución Libre de Enseñanza y tratando de establecer paralelismos con los fundamentos del nuevo proyecto de ley de educación ${ }^{2}$ que actualmente se encuentra en tramitación parlamentaria en España.

Palabras clave: Institución Libre de Enseñanza; educación secundaria; nuevo proyecto de ley de educación; metodologías.

\footnotetext{
1 Máster Universitario en Formación del Profesorado de Educación Secundaria Obligatoria y Bachillerato, Formación Profesional y Enseñanzas de Idiomas. Universidad Nacional de Educación a Distancia (UNED), España. Profesor del Aula Permanente de Formación Abierta (Sede de Ceuta). Universidad de Granada, España. Email: jgutierre750@alumno.uned.es

2 Proyecto de Ley Orgánica por la que se modifica la Ley Orgánica 2/2006, de 3 de mayo, de Educación.
} 


\begin{abstract}
The Institución Libre de Enseñanza wanted to redefine the raison d'être of the second education. With the arrival of the civil war the Institución disappears and, with it, all the pedagogical innovations that were implemented. The reinstatement of democracy brings with it the approval of successive educational laws that try to adapt the Spanish educational system to each specific social situation. The purpose of this essay is to help define the being of the second education in the Spanish educational field, relying on the pedagogical principles that guided the educational work of the Institución Libre de Enseñanza and trying to establish parallels with the basis of the new bill of education that is currently in its parliamentary procedure in Spain.
\end{abstract}

Keywords: Institución Libre de Enseñanza; secondary sducation; new bill of education; methodologies.

\title{
1. Introducción/ Introdução
}

La Institución Libre de Enseñanza (ILE) es una iniciativa pedagógica que surge en España en el último cuarto del siglo XIX de la mano de varios pensadores y profesores universitarios que fueron conscientes de la decadencia moral y ética en la que se encontraba la educación en aquel momento. Este conjunto de profesores, entre los cuales destaca Francisco Giner de los Ríos, se forman en la filosofía krausista, introducida en nuestro país por Julián Sanz del Río, así como en los métodos pedagógicos de Juan Enrique Pestalozzi, Federico Fröbel o, remontándonos más aún en el tiempo, Juan Jacobo Rousseau.

En 1876 ve la luz la ILE y muy pronto sus iniciadores se dan cuenta de que es en la enseñanza secundaria donde habrían de centrar sus principales esfuerzos. En efecto, si bien la Institución nace para dedicarse al ámbito universitario (en gran parte debido a que es en este ámbito donde ejercían muchos de los iniciadores de este proyecto pedagógico), en 1881 deja de ser universitaria para dedicarse a lo que Giner gusta en llamar educación general (que engloba, como veremos, tanto a la primera como a la segunda enseñanza) (Molero, 2000). Por 
eso, Francisco Giner de los Ríos y el resto de los institucionistas empiezan a configurar una educación secundaria completamente renovada, en clara continuación con la primaria, con sentido finalista y en sí misma, que se preocupe por la educación y por la formación integral de las personas antes que por la instrucción, concebida exclusivamente como transmisión de conocimientos. Giner y sus compañeros crearon una escuela donde la coeducación fuera la base, siendo así fiel reflejo de la sociedad en la que conviven hombres y mujeres, y donde se apostaba por metodologías activas, haciendo así de los alumnos los protagonistas de sus propios aprendizajes. Basándose en lo que ellos llamaban pedagogía de la intuición, los institucionistas crearon una relación entre profesores y alumnos que hizo de la escuela una prolongación del ámbito familiar.

Sin embargo, debido entre otros factores a la neutralidad religiosa dentro de las aulas que propugnaban y a la introducción de las ideas de Carlos Christian Federico Krause, la Institución fue objeto de severas críticas por parte de la Iglesia católica y de gran parte de los sectores políticos conservadores. El fallecimiento de Francisco Giner de los Ríos en 1915 fue posiblemente un elemento que contribuyó a polarizar aún más las relaciones entre ambos sectores. De esta manera, las escuelas de la Segunda República española, de clara inspiración institucionista, fueron bastante más radicales (en cuanto a las cuestiones religiosas se refiere) que las que existieron en los primeros años de vida de la ILE. La reacción del nacionalcatolicismo no se hizo esperar $y$, al vencer la guerra, acabó con todo vestigio institucionista en la sociedad española durante la dictadura posterior.

Tras la muerte de Franco, España entra en la etapa democrática actual, durante la cual nuestro país ha sido testigo de la aprobación e implantación de diversas leyes educativas. Cuando un nuevo Proyecto educativo está siendo tramitado actualmente en el Congreso de los Diputados, este trabajo pretende unir ambos aspectos: los principios pedagógicos de la Institución Libre de Enseñanza y las claves del nuevo proyecto de ley, particularizados en el currículo de la educación secundaria.

El presente trabajo se estructura a través de una serie de puntos que van a permitir, en el apartado de conclusiones, establecer una comparación entre la 
concepción que la ILE tenía de la secundaria y la que plantea la que se puede convertir (o no) en la octava ley educativa desde la restauración de la democracia.

\section{Razón de ser de la Educación Secundaria}

\section{1. ¿Concepción finalista o preparatoria?}

En la primera mitad del siglo XIX la concepción predominante de la enseñanza secundaria en los textos legales del momento no le da un sentido en sí misma, sino que la comprende simplemente como una preparación para el acceso a la Universidad. Esta era, por lo demás, la concepción mayoritariamente seguida en los países de nuestro entorno, y no será hasta finales del siglo cuando se empiece a entrever la continuidad entre la primera y la segunda enseñanza (Viñao, 1982).

En nuestro país será la Institución Libre de Enseñanza la que lleve a cabo la oposición a la concepción preparatoria de la secundaria. En efecto, los años que preceden al nacimiento de la ILE hacen germinar en su fundador una concepción de la enseñanza secundaria radicalmente diferente a la que había sido común durante los gobiernos liberales del siglo XIX en España. De esta manera, inspirado por los principios educativos del fallido sexenio revolucionario, Francisco Giner de los Ríos se opone abiertamente a considerar esta etapa como una serie de estudios preparatorios para ingresar en la Universidad, por lo que la empieza a concebir más bien con una significación en sí misma (Puelles, 2010). Así lo expresa el propio Giner de los Ríos (1927, p. 140):

Difícil será negar que todos los órdenes de la educación en su variedad infinita se reducen, bajo el aspecto cualitativo, exclusivamente a uno de estos dos: la educación general del individuo, puramente como tal, o su preparación especial para un fin determinado, y la segunda enseñanza ha correspondido siempre al primer grupo.

A pesar de la claridad con la que se expresa el fundador de la ILE, tradicionalmente en España la educación secundaria ha sido entendida mayoritariamente como una preparación para otros fines antes que con un sentido en sí misma. En efecto, «la educación secundaria ha tenido siempre un carácter 
bifronte: propedéutica, porque prepara para una profesión de nivel superior; terminal, porque proporciona los conocimientos necesarios para el ingreso en la vida activa. De hecho, en España los gobiernos han solido inclinarse más de un lado que de otro» (Puelles, 2011, p. 717).

Sin embargo, con el nuevo proyecto de ley de educación se adopta un equilibrio entre ambas posiciones ya que la segunda enseñanza, por una parte, debe propiciar que los alumnos adquieran los elementos básicos de la cultura en todas sus dimensiones, desarrollen y consoliden sus hábitos de estudio y se formen en el ejercicio de sus derechos y obligaciones en la vida como ciudadanos (lo cual entraría a formar parte de la concepción finalista) y, por otra, prepararles para los estudios posteriores o incorporarles al mundo del trabajo (lo cual se insertaría en la concepción preparatoria de la enseñanza secundaria).

\subsection{Continuidad entre la primera y la segunda enseñanza}

También en este aspecto se produce una confrontación con la concepción que tenía el liberalismo moderado acerca de esta etapa educativa. En efecto, Francisco Giner de los Ríos, además de comprender la educación secundaria en sentido finalista, la entiende en íntima conexión con la primaria, ya que constituye su complemento necesario para hacer del hombre un ciudadano capaz de integrarse en la sociedad (Puelles, 2010).

Siguiendo la estela del pensamiento de Pestalozzi, uno de sus mayores inspiradores pedagógicos, la concepción de educación para Giner de los Ríos es la de una educación general (o integral, sin rupturas entre primaria y secundaria) (Turín, 1967) que considera la segunda enseñanza como una continuación y desarrollo de la primera y que, si se separa en dos momentos, es para dar respuesta al desarrollo madurativo del niño, que en un momento determinado necesita que se adapte la educación a su propio proceso (Puelles, 2010). Así lo expresa el propio Giner (citado en Jiménez García, 1985, p. 156):

Parece evidente que las llamadas enseñanzas primaria y secundaria corresponden a un mismo proceso del que, a lo sumo, constituyen dos grados, bastante difíciles de distinguir, enlazados solidariamente, merced a 
la identidad de su fin común, inspirados de un mismo sentido y dirigidos según unos mismos programas, una misma organización y unos mismos métodos. No hay entre ellos otras diferencias que las que en el desarrollo de estos elementos exige la evolución natural del educando y sus facultades, cuya suave continuidad va cada vez pidiendo nuevas condiciones en aquella aplicación. Pues, si tomamos como punto de partida para la segunda enseñanza la crisis normal de la pubertad, lo que precisamente exige esta crisis no es una nueva orientación, ni otros principios [...].

Queda claro que Francisco Giner de los Ríos defiende la educación más bien como un proceso gradual y total, y no como etapas distintas o compartimentos estancos, con contenidos y métodos diferentes. Es esta misma concepción la que va asumiendo hoy la enseñanza secundaria al empezar a ser considerada como una extensión de la primaria, dejando así de lado la tradicional vinculación con la Universidad que le ha caracterizado (Bolívar, 2015).

Esta misma línea de continuación entre la primaria y la secundaria es la que abandera también el nuevo proyecto de ley de educación, dados los puntos de conexión que mantiene con la Ley Orgánica de 2006 (LOE). En efecto, desde la misma exposición de motivos el Proyecto sostiene que se van a añadir una serie de precisiones sobre la educación básica con la finalidad de garantizar la continuidad, coordinación y cohesión entre las dos etapas que la componen). Ya en el articulado del Título Preliminar se afirma que «la educación primaria y la educación secundaria obligatoria constituyen la educación básica» (MEFP, 2019b, art. 3.3), cuya regulación es objeto del siguiente artículo. Hay que destacar lo que afirma el segundo párrafo del apartado segundo del mismo, novedoso en la redacción del proyecto de ley. En él se dice que «con el fin de garantizar la continuidad, coordinación y cohesión entre las dos etapas de la educación básica, las Administraciones educativas adoptarán las oportunas medidas de carácter organizativo y curricular» (MEFP, 2019b, art. 4.2).

Por lo tanto, el nuevo proyecto concibe la educación secundaria en íntima conexión con la primaria, tal y como los institucionistas visionaron para la ILE. 


\section{Fin de la Educación Secundaria}

\subsection{La educación como complemento a la instrucción}

Francisco Giner de los Ríos y los filósofos procedentes del krausismo en general están tremendamente preocupados por la tensión existente entre educación e instrucción. Dado que los seres racionales son mucho más que repetidores mecánicos de lo que aprenden y que tienen potencias naturales que no se desarrollan a la par que la inteligencia, la enseñanza tradicional del momento, inclinada más hacia el lado de la instrucción (para la cual el niño es considerado como un simple recipiente vacío que hay que ir llenando de conocimientos y saberes), pedía urgente reforma (Giner de los Ríos, 1933).

La postura que defiende Giner es radicalmente la contraria: el fundador de la ILE concibe la instrucción en un segundo lugar y con un carácter subsidiario a la educación, la cual es entendida como la formación de personas libres que sean capaces de moverse con forma y criterio en la sociedad en la que viven (Jiménez García, 1985). Por lo tanto, el empeño de la Institución Libre de Enseñanza es educar (más que instruir) «al hombre como tal hombre, en la unidad y armonía de todas sus fuerzas» (Giner de los Ríos, 1927, p. 161).

En la sociedad del siglo XXI la educación secundaria debería dedicarse también a desarrollar las capacidades básicas del alumnado (que se expresarán operativamente en las competencias educativas) más que a darles paquetes de conocimientos que habrán de ser asimilados mecánica y pasivamente (Escámez y Sanz, 2011). Así, al anteponer el aprendizaje por competencias a la recepción pasiva y memorística de los conocimientos se hace más hincapié en la educación que en la instrucción.

En esta línea, el nuevo proyecto de ley apuesta por un aprendizaje por competencias (así se desprende de los artículos 22.8 y 26.2, que invitan a prestar atención a la adquisición y desarrollo de las competencias básicas, así como a potenciar un aprendizaje de carácter significativo para poder desarrollar las competencias que promuevan la autonomía y la reflexión) y, por ende, se sitúa en la concepción gineriana de la educación. 


\subsection{La educación, motor de la transformación del hombre y de la sociedad}

A la vista de que la experiencia revolucionaria de años anteriores no pudo desde arriba cambiar radicalmente al conjunto de la nación para hacerla más abierta y tolerante, europeísta e integradora de la diversidad y multiformidad que caracteriza a nuestro país, Francisco Giner de los Ríos pretende llevar a cabo esa transformación de nuevo, pero en este caso desde abajo. Para ello, el alma mater de la Institución necesita conformar hombres espontáneos y libres y así hacer de España un país democráticamente estable (Jiménez García, 1985).

Movido por los principios del krausismo, Giner de los Ríos está plenamente convencido de que será mediante la educación como se puede alcanzar la renovación del hombre. Y solo haciendo de los educandos seres humanos nuevos se podrá conseguir también la transformación moral de la sociedad española del momento. En la mente de Giner subyace, pues, la idea de modernizar la nación y de inculcar en los ciudadanos una ilusión colectiva por el progreso ético y cultural (Puelles, 2010).

La huella del krausismo a través de sus valores morales y éticos se deja sentir de nuevo al ponerse de manifiesto que el propósito de la ILE será, además, el de formar hombres con un gran sentido de la responsabilidad, gusto e iniciativa con la finalidad de ser útiles en el servicio de la humanidad y de la patria (Turín, 1967).

La misma idea institucionista subyace, aunque con un lenguaje sustancialmente distinto, en el art. $2.1 \mathrm{k}$ del nuevo proyecto de ley, donde se pone de manifiesto que la educación debe preparar para el ejercicio de la ciudadanía activa y para la participación en la vida económica, social y cultural, con actitud crítica y responsable. Así también en el art. 6.2 se afirma que «el currículo irá orientado a facilitar el desarrollo educativo de los alumnos y alumnas, garantizando su formación integral, contribuyendo al pleno desarrollo de su personalidad y preparándoles para el ejercicio de una ciudadanía activa y democrática en la sociedad actual». 
Si bien es verdad que en el proyecto no se aboga por una transformación social ni por una modernización de la patria, lo que se está poniendo de manifiesto es que la educación debe propiciar que los alumnos se incorporen como ciudadanos libres y responsables en la sociedad de su momento, lo cual se consigue si reciben los conocimientos y competencias indispensables tanto para su desarrollo personal como para desarrollar su socialización.

\section{Objetivo de la Educación Secundaria: una educación integral}

"La preocupación máxima de Giner fue en todo momento el ideal de la educación del hombre por el hombre a partir del desarrollo integral de las propias aptitudes y capacidades" (Jiménez García, 1985, p. 149). Quiere esto decir que la educación general (primaria más secundaria) debe constituir una formación que vaya más allá de los conocimientos, aunque naturalmente los incluya. De esta manera, el objetivo de la educación secundaria no puede ser otro que proporcionar una educación integral, al más puro estilo de Pestalozzi. Así lo expresa el propio Giner de los Ríos (1927, p. 167):

La educación general, primaria como secundaria, jamás puede consistir, no ya en la mera instrucción, mas ni en el desenvolvimiento puramente intelectual, sino que ha de promover íntegramente el sentimiento y la voluntad, como el conocimiento; el carácter moral, como el desarrollo y fuerza físicos; disponiendo, en suma, al joven para entrar como hombre en el concierto de la sociedad y el mundo.

Se trata de una acción educativa completa, que va a afectar a todos los planos posibles de la personalidad y que se ha de guiar por imperativos éticos. Una concepción integral que abarca también tanto los aspectos externos como los internos de la personalidad y que van desde elementos tan esenciales como la higiene hasta el desarrollo de la solidaridad con toda la humanidad. Educación integral que va a estar especialmente guiada por ideales éticos y que se centrará en los aspectos intelectual, físico y afectivo (Molero, 2000).

Como sostiene nuestra Constitución en el artículo 27.2, el pleno desarrollo de la personalidad humana ha de convertirse en la finalidad última que el sistema 
escolar ha de conseguir. De esta manera, el marco normativo legal de nuestro país se sitúa en la concepción gineriana que apuesta por la educación integral de las personas. Una educación integral que, para el proyecto de ley de educación, ha de verse en relación con el aprendizaje por competencias, las cuales, según se dispone desde la misma exposición de motivos, habrán de ser trabajadas desde todas las áreas de conocimientos. Así, junto a los conocimientos, hay que destacar el aprender a hacer que suscitan las competencias, a lo que hay que añadir un acento especial en la educación emocional y en valores, en la formación estética y en la creatividad (MEFP, 2019b). El nuevo proyecto comprende lo que es el hombre desde su ser más profundo y, por ello, apuesta decididamente por una educación de tipo integral en conocimientos, destrezas y valores, que garantice una igualdad de oportunidades para el pleno desarrollo de la personalidad en toda la enseñanza secundaria.

\section{Metodologías y evaluación en Educación Secundaria}

\subsection{Una educación activa}

Para lograr su propósito de educar personas libres que sean capaces de moverse con criterio en la sociedad en la que viven, Francisco Giner de los Ríos apuesta por una metodología activa que se va a oponer radicalmente a la propia de la enseñanza tradicional. En efecto, si la enseñanza del momento sigue unidireccionalmente el camino profesor-alumno, considerando simplemente a este último como receptáculo del conocimiento, la apuesta de Giner de los Ríos es por la actividad, es decir, por motivar al niño a través del método socrático y fundamentalmente a través de la intuición (Jiménez García, 1985).

Con otras palabras, por educación activa hemos de entender el pensamiento en acción, es decir, la participación del alumno en su propio proceso formativo (Molero, 2000). El deseo de Giner consistirá, por tanto, en que los escolares, en pequeños círculos, piensen, hablen, discutan, se muevan, colaboren con el maestro, que experimenten en el laboratorio, interpreten los textos, inventen, descubran, adivinen. En suma, en hacer de la cátedra un taller, del 
maestro un guía en el trabajo, de los discípulos una pequeña familia (Giner de los Ríos, 1933).

La apuesta por unos métodos y procedimientos activos (en los que los aprendices sean los propios constructores de sus propias capacidades en interrelación con los docentes y sus propios compañeros) se hacen necesarios para que los alumnos construyan sus propias competencias lógicas y morales (Escámez y Sanz, 2011). Como sostiene el art. 2f del proyecto de ley, entre los fines de la educación se encuentra que los alumnos sean capaces de regular su propio aprendizaje confiando en sus aptitudes y conocimientos, desarrollando la creatividad, la iniciativa personal y el espíritu emprendedor. Asimismo, en el art. 26.1, dedicado a los principios pedagógicos de la Educación Secundaria Obligatoria, se incide de nuevo en favorecer la capacidad de los alumnos de aprender por sí mismos y de trabajar en equipo. El alumno, participando en la construcción de su propio aprendizaje, está aportando a su propio proceso formativo.

\subsection{La pedagogía de la intuición}

Para acabar con lo que consideraban uno de los vicios más comunes en las escuelas del momento (la memorización), los institucionistas abogan por el método intuitivo en educación. Dicho método no es más que lo que hoy se entendería como aprendizaje por proyectos. En efecto, el propio Francisco Giner de los Ríos sostiene que «la naturaleza del procedimiento intuitivo no está en confirmar a posteriori la exactitud de una exposición previa, sino en llevar de la mano al alumno, para que él mismo, partiendo de los datos que se le presentan, pueda resolverlos en un sistema de conceptos» (citado en Molero, 2000, p. 98).

Con el convencimiento de que la enseñanza de un ser libre, como es el ser humano, debe consistir en algo completamente distinto de la constante repetición, el método intuitivo sustituye a la coacción, la obligación y la mecanización en la realización de actividades por el esfuerzo personal, la espontaneidad y un trabajo escolar atrayente. Además, la complementariedad que debe existir entre la instrucción y la educación se mezcla en la pedagogía intuitiva al formarse no solo 
la inteligencia (ayudando a pensar y a escuchar), sino también el carácter, manifestado en el estudio y en el trabajo autónomo (Turín, 1967).

Así, la intuición desarrolla la espontaneidad y la creatividad del alumno y lo transforma de sujeto pasivo en sujeto investigador. No se trata, por lo tanto, de concebir la enseñanza como una transmisión unidireccional, donde el docente sea el transmisor y el discente el receptor de los conocimientos, sino en proporcionar al estudiante actividades en orden creciente de dificultad para que las resuelva y aplique a diferentes situaciones.

Hay que aprovechar la capacidad indagadora e investigadora que tiene de manera innata el alumno para que se sienta movido a realizar iniciativas que le faciliten su propio descubrimiento de las cosas. Las frecuentes excursiones educativas que realizaban los componentes de la Institución ayudaron sobremanera a desarrollar esta pedagogía de la intuición al permitir al alumno leer la naturaleza de muchas y variadas maneras, desde la búsqueda de la relación entre causas y efectos hasta la contemplación estética de la misma (Molero, 2000).

Tal y como está redactado el proyecto, no se hace ninguna referencia al tipo de actividades que se puedan desarrollar dentro de las aulas, algo que seguramente será objeto de desarrollos legislativos de menor rango que concretarán los principios generales sobre los que se asienta por propia esencia toda ley orgánica. Sin embargo, «diseñar situaciones de aprendizaje para que el alumnado explore y descubra por sí mismo, en relación con los compañeros» (Escámez y Sanz, 2011, 54) ha de ser una de las tareas que deben afrontar los docentes de secundaria. Lo que Giner de los Ríos concibe como pedagogía de la intuición, más de un siglo después, ha de seguir formando parte del modus operandi de quien se dedique a la enseñanza en esta etapa educativa.

\subsection{La relación constante entre profesor y alumno como forma de evaluar}

Respecto del sistema de evaluación, Giner propugna un abandono de los exámenes, a los que calificaba de sistema corruptor, debido a que impedían 
cualquier intento de innovación. Igualmente, los institucionistas combatieron el uso de los clásicos libros de texto como única fuente de conocimiento.

En lugar de todo ello, desde la misma educación primaria los miembros de la Institución intentan favorecer una enseñanza basada en la consulta de fuentes variadas y en la toma de notas, lo cual debía quedar plasmado en el cuaderno elaborado por cada alumno y que venía a ocupar el lugar de los tradicionales libros de texto. En consecuencia, los deberes de casa no tenían sentido, así como tampoco un aprendizaje memorístico. Con este cambio de perspectiva didáctica, ni los premios ni los castigos podían ocupar lugar alguno (Molero, 2000).

Esa relación entre profesor y alumno cambia la perspectiva de las tradicionales lecciones magistrales a las conversaciones que se establecen entre ambos, basado en un método de preguntas mutuas y entre los propios alumnos. En palabras del propio Giner de los Ríos (1933, p. 24): «(Las lecciones) deben venir a ser una reunión durante algunas horas, grata, espontánea, íntima, en que los ejercicios teóricos y prácticos, el diálogo y la explicación, la discusión y la interrogación mutua alternen libremente con arte racional, como otros tantos episodios nacidos de las exigencias mismas del asunto».

Con una terminología actual, el proyecto de ley entiende la evaluación del alumnado de manera continua, formativa e integradora (MEFP, 2019b), en línea con lo establecido por la ley actualmente en vigor. Así lo particulariza el art. 28.1 para el caso de la Educación Secundaria. Es decir, lejos de los tradicionales exámenes como método casi único de evaluación de los alumnos, el nuevo proyecto se alinea (como ya lo hacía la LOE en 2006) con el planteamiento institucionista pues, para lograr que la evaluación posea estas tres características, hace falta que el papel del docente sea activo y en comunicación constante con los estudiantes, para poder así percatarse de las carencias y necesidades de cada uno y hacerles propuestas de mejora. Solo así la evaluación podrá ser formativa a la vez que integradora. 


\section{Proyecto de apertura: čhacia la comprensividad en educación?}

Es verdad que en los orígenes de la ILE no existía el planteamiento de crear una secundaria para todos, pero también es cierto que en la pedagogía de la época eso era algo impensable. No obstante, la naturaleza del proyecto institucionista hizo que, entrados ya en el siglo XX, la educación secundaria, como parte integrante de una educación general que desarrollaba la primaria, debía extenderse a toda la población, como ya se hizo con la primaria un siglo atrás.

Se van poniendo así las bases de la que, mediado el siglo XX, será llamada educación comprensiva. En efecto, la concepción de una educación general que abarque a la primaria y a la secundaria como partes de un mismo proceso, con los mismos métodos y fines, que promueve la educación integral de la persona y que se extiende a toda la población de forma gratuita sientan las bases para el surgimiento de esa educación comprensiva (Puelles, 2010).

La Institución Libre de Enseñanza da origen a este tipo de comprensividad en educación, concepto este que, gracias a la labor de pedagogos como Lorenzo Luzuriaga, es asumido bajo el nombre de escuela unificada en la época de la Segunda República española. La dictadura de Franco rompe esta concepción, que no se recuperará hasta la aprobación de la Ley General de Educación (LGE) en 1970. Será en 1990 con la Ley de Ordenación General del Sistema Educativo (LOGSE) cuando se alcanzan las más altas cotas de comprensividad, al hacer especial hincapié en la escolarización común de todos los alumnos sin discriminación, sin separación por diferentes niveles de rendimiento académico, discapacidades o necesidades educativas especiales. La introducción de itinerarios diversificados a partir del tercer curso de secundaria y la facilidad para ejercer la libertad de elegir escuela, pilares básicos de la Ley Orgánica de Calidad de Educación (LOCE) de 2002 (que no llegó a entrar en vigor), atacan la concepción de comprensividad. Con la aprobación de la LOE en 2006, en un contexto crecientemente multicultural, se vuelve a insistir en la comprensividad, entendida como inclusión, igualdad de trato y no discriminación de las personas bajo ningún concepto. La Ley Orgánica de Mejora de la Calidad Educativa (LOMCE), actual ley 
que entró en vigor en 2013, recupera los aspectos que la LOCE no pudo llevar a cabo, volviendo así a una ruptura de la comprensividad (Bolívar, 2015).

Esta situación es la que pretende revertir el nuevo proyecto de ley de Educación. En efecto, si escuela comprensiva es «una forma de organización escolar donde el primer nivel de educación secundaria es continuación de la educación general o básica, teniendo entre sus objetivos la igualdad de oportunidades y la atención a la diversidad» (García Pedraza, 2015, p. 140), entonces estos dos últimos aspectos van a resultar claves para entender la comprensividad actualmente. Ya desde la misma exposición de motivos del proyecto queda clara esta posición en defensa de la comprensividad educativa, al apostar nítidamente por una educación de calidad para todos que no deje de lado la equidad ni la inclusión de todos los alumnos en el seno de esta sociedad multilingüe y cosmopolita (MEFP, 2019b).

\section{La religión en la Educación Secundaria}

La posición de la Institución Libre de Enseñanza respecto de la enseñanza de la religión es de neutralidad. Resulta llamativo que sea este principio (y no el de laicidad) el que abandere la ILE. De esta manera, la religión, lejos de quedar recluida en los templos y en las familias, debía seguir formando parte de la escuela, lo cual no debería sorprender pues el objetivo que persigue la educación secundaria es la educación integral y, como tal, la religión debe estar presente.

No obstante, los institucionistas sí están en contra de que la religión que se enseñe en las escuelas sea de tipo confesional, por lo que en el currículo de la secundaria debería aparecer esta como un fenómeno cultural que todos deben conocer y respetar (Puelles, 2010) ${ }^{3}$.

La tolerancia hacia todas las religiones llegaba hasta el punto de que, cuando se realizaban excursiones dominicales con los alumnos de la ILE, los

\footnotetext{
${ }^{3}$ De lo que se trataría es de estudiar el hecho o el fenómeno religioso ya que, más allá de las creencias particulares de cada cual, no se puede obviar que la apertura a la trascendencia forma parte de la vida de los seres humanos, aunque sea para negarla. Motivo más que suficiente para que, desde la educación integral de las personas, no se deje de lado esta cuestión crucial. Este es el punto en el que probablemente haya más discrepancias entre la pedagogía de la ILE y la filosofía de fondo del proyecto de ley de educación.
} 
institucionistas abogaban por que aquellos que profesaban el catolicismo cumplieran con sus compromisos religiosos. $Y$ es que el fundador de la Institución estaba convencido de que la tolerancia religiosa debía ser una condición esencial de la enseñanza, pues a partir de ella se sentarían las bases para la convivencia española (Jiménez García, 1985). Así lo expresa el propio Giner de los Ríos (1933, p. 76-77):

Si hay una educación religiosa que deba darse en la escuela, es esa de la tolerancia positiva, no escéptica e indiferente, de la simpatía hacia todos los cultos y creencias, considerados cual formas, ya rudimentarias, ya superiores y aun sublimes, como el cristianismo, pero encaminadas todas a satisfacer sin duda en muy diverso grado -en el que a cada cual de ellas es posible- según su cultura y demás condiciones, una tendencia inmortal del espíritu humano.

En suma, lo que los institucionistas, al menos los de la primera época, perseguían era un proyecto secularizador de la sociedad que intentaba inculcar la tolerancia y el respeto en los estudiantes y que quería mantenerse alejado tanto de posturas anticatólicas como acérrimas defensoras de la fe. Sin embargo, posicionarse, aunque solo fuera desde la neutralidad, contra la Iglesia hizo que la ILE fuese acusada por el integrismo católico de la época y de años posteriores de antirreligiosa, acusación que muy probablemente le supuso su condena a muerte nada más alzarse el franquismo con el poder.

Durante la dictadura la Iglesia católica consiguió que la religión apareciera como asignatura en las escuelas. Con la aprobación de la Constitución de 1978 y la posterior firma de los Acuerdos Iglesia-Estado en 1979, la religión, aun pasando a ser una asignatura de oferta obligatoria para los centros (en igualdad de condiciones que el resto de materias) pero de elección voluntaria por parte de los alumnos, seguía estando en los currículos educativos, a pesar de la variedad de alternativas que ha tenido (necesarias, ya que no es permisible que algunos alumnos en horario escolar cursen una asignatura, mientras que otros no lo hagan). Sin embargo, coincidiendo con Díez de Velasco (2016, p. 286-287), el planteamiento de fondo es equivocado ya que 
educar en la diversidad no es [...] enseñar desde lo singular, ni tampoco hacerlo desde una multiplicación de las opciones por lo singular [...] Enseñan religión (sea católica, evangélica, islámica, judía o las que pudieran incluirse) pero no religiones [...] Se puede afirmar de hecho que [...] no son propuestas de enseñanza integrada, que sería el camino adecuado desde el punto de vista teórico, sino segregada, y se basan en dar carta de naturaleza a un aula que busca la integración en las demás asignaturas pero admite la segregación cuando el foco se centra en las creencias religiosas.

La postura defendida por Francisco Giner de los Ríos en la Institución Libre de Enseñanza acerca de la neutralidad en la enseñanza de la religión no segrega a nadie en virtud de su confesión particular y ofrece un conocimiento religioso para todos que contribuyese a la formación integral de la persona. Para poder alcanzar tal situación hoy en día sería necesario que se revisasen los Acuerdos IglesiaEstado, algo que hasta ahora ningún gobierno ha pretendido hacer. Por eso, a pesar de la segregación que conlleva, la solución legal más conveniente al tema que nos ocupa radicaría en que la alternativa a la religión confesional fuese una materia que abordase el fenómeno o el hecho religioso.

El nuevo proyecto de ley de educación no va en esa dirección. De hecho, la única mención a este aspecto la encontramos en la disposición adicional segunda, cuyo primer apartado dice así:

La enseñanza de la religión católica se ajustará a lo establecido en el Acuerdo sobre Enseñanza y Asuntos Culturales suscritos entre la Santa Sede y el Estado español. A tal fin, y de conformidad con lo que disponga dicho Acuerdo, se incluirá la religión católica como área o materia en los niveles educativos que corresponda, que será de oferta obligatoria para los centros y de carácter voluntario para los alumnos y alumnas.

Tal parquedad únicamente se ve completada en el dossier de presentación del proyecto, donde se afirma que no existirá para ella una asignatura espejo para la materia de religión católica (MEFP, 2019a). El distanciamiento en este tema entre la pedagogía de la ILE y la del proyecto de ley es total, postura que además estaría rozando los límites constitucionales al permitir que haya alumnos que 
cursen una asignatura, mientras que otros no tengan ninguna materia alternativa en ese espacio de tiempo.

\section{Conclusiones}

Es el momento de poner ahora de relieve los paralelismos y las discordancias encontradas entre los planteamientos pedagógicos analizados de la Institución Libre de Enseñanza y los del nuevo proyecto de ley de educación en lo que a la segunda enseñanza se refiere. En primer lugar, para los institucionistas la secundaria debe tener una entidad propia y en sí misma. Hasta la LGE ha predominado, sin embargo, la concepción preparatoria para el bachillerato o el mundo del trabajo aunque, desde entonces, se ha querido dar a la secundaria un sentido más acorde con su propio ser. El nuevo proyecto intenta reconducir un poco esa concepción preparatoria sin lograrlo del todo. Por ello, el proyecto queda a medio camino entre la posición de la ILE y la de la secundaria tradicional, abogando por un equilibrio entre ambas. No obstante, donde sí que hay concordancia total es en considerar la existencia de una continuidad entre la primaria y la secundaria, como ha quedado de manifiesto más arriba. Algo que, en cambio, resulta un poco paradójico y que no hace más que poner de relieve la intención del proyecto de virar hacia los planteamientos institucionistas, pero terminar quedándose a medio camino.

Un punto en el que tanto la Institución Libre de Enseñanza como el nuevo proyecto coinciden, aunque lo expresan de forma diversa, debido sobre todo a que el contexto de finales del siglo XIX y comienzos del XX no tiene mucho que ver con el de principios del XXI, es en considerar que, en la segunda enseñanza, se debe educar antes que instruir. O dicho de una manera más actual, los docentes de secundaria han de procurar que sus alumnos adquieran las competencias clave por encima de la mera trasmisión de conocimientos. La educación es un concepto muy amplio asociado hoy en día con la adquisición de las competencias, mientras que la instrucción tendría más que ver con la transmisión de conocimientos. 
Dado que tanto la ILE como el nuevo proyecto entienden que hay que educar más que instruir, ambos también coinciden en el fin de esa educación: la transformación de los hombres y de la sociedad. Lo que, en la terminología reciente, se traduce en una concepción integral de la educación (también defendida por los institucionistas) gracias a la adquisición de las competencias clave, cuyo objetivo es ayudar a que los alumnos se incorporen en la sociedad como ciudadanos activos, libres y responsables que se preocupen por su aprendizaje permanente a lo largo de sus vidas.

Descendiendo al plano metodológico, ambos apuestan por implementar metodologías activas en el interior del aula, lo cual quiere decir que el alumno ha de convertirse en el protagonista de su propio proceso de aprendizaje. Los institucionistas iniciaron aquí lo que actualmente podría llamarse aprendizaje por proyectos, aunque el proyecto de ley no hace referencia, en su redacción actual, a ninguna metodología en particular. Esa parquedad hace que no haya ninguna referencia a lo que los miembros de la ILE conocieron como pedagogía de la intuición. No obstante, cabe esperar que en desarrollos legislativos posteriores sí se vea alguna concreción al respecto, dado que estos aspectos encuentran su lugar en alguna Orden Ministerial, como la ECD/65/2015, de 21 de enero, actualmente en vigor y que supone la concreción metodológica de los principios de la LOMCE.

En el plano evaluativo la Institución Libre de Enseñanza apuesta por una evaluación sin exámenes, para lo cual la relación constante entre el profesorado y el alumnado, así como el trabajo diario de este, puesto de manifiesto en su propio cuaderno, se van a volver de crucial importancia. En este sentido, el nuevo proyecto de ley, siguiendo la estela de la LOE, vuelve a entender la evaluación como continua, formativa e integradora. Para lograrla, si bien no se hace mención expresa a los exámenes (como tampoco a ninguna otra forma de evaluar), parece claro que el tradicional método de los exámenes no sería el más apropiado para conseguir tal forma de evaluación.

Respecto a la comprensividad, término que aparece a mediados del siglo XX, la Institución Libre de Enseñanza no podía decir mucho al respecto. Sin 
embargo, el hecho de que considerase la educación secundaria abierta y extendida a toda la población, algo novedoso en aquel contexto sociocultural, hace pensar que, de no haber abruptamente desaparecido con el inicio de la dictadura, habría hecho gala de esa concepción educativa. El proyecto de ley, después de todos los vaivenes habidos a lo largo de las sucesivas leyes educativas, apuesta decididamente por la comprensividad en educación.

En último lugar, el aspecto con más discrepancia entre el posicionamiento pedagógico de la ILE y el del proyecto, más incluso que en lo que se refiere a la concepción finalista de la secundaria. Se trata de la enseñanza (o no) de la religión en las escuelas. Los institucionistas de la primera época ${ }^{4}$, y Francisco Giner de los Ríos fue claro al respecto, apostaban por la neutralidad en materia religiosa, apuesta fuerte dada la sociedad católica de la época. Ello no quiere decir, aunque se haya interpretado así en mucho ámbitos (tanto por parte de los enemigos, con Marcelino Menéndez Pelayo a la cabeza, como del ámbito de influencia de la propia ILE, pues ello derivó en la escuela laica de la Segunda República, en el seno de una sociedad antirreligiosa), que se debiera excluir la enseñanza religiosa de la escuela. Al contrario, Giner de los Ríos veía necesaria la enseñanza del hecho religioso (no desde un punto de vista confesional, eso sí) dentro de la escuela para contribuir así a la educación integral del ser humano, hasta el punto de tolerar las creencias de sus alumnos católicos e incluso propiciar que, durante las famosas excursiones pedagógicas que realizaban, asistieran a las celebraciones eucarísticas de los domingos. La posición que enarbola el proyecto de ley de educación es poco novedosa al respecto: oferta obligatoria de la religión católica en las escuelas, pero de elección voluntaria por los alumnos y sin asignatura espejo. El proyecto, así, sigue segregando a los alumnos (al dividir el aula entre los que dan religión y los que no, que no gozarían con la redacción actual del proyecto de otra asignatura en su lugar) y no ofrece la posibilidad de

\footnotetext{
${ }^{4}$ Es importante señalar que la misma Institución sufre una evolución ya que, especialmente tras la muerte de Giner, algunos institucionistas se muestran más beligerantes hacia la cuestión religiosa. En particular, Fernando de los Ríos, ministro de la Instrucción Pública entre 1931 y 1933, era partidario de una escuela laica donde la religión fuera excluida, muy en consonancia con la ideología de la Segunda República.
} 
comprender el hecho religioso a quienes no eligen cursar religión católica, mermando así la integridad educativa mencionada más arriba. Dado que la postura de la ILE no es posible llevarla a cabo mientras no se revisen los Acuerdos Iglesia-Estado, el nuevo proyecto debería ofrecer, no solo religión católica, sino una alternativa que estudie el fenómeno o el hecho religioso para el resto de los alumnos que no opten por la versión confesional.

Muchos son los puntos concordantes entre ambas iniciativas pedagógicas. Sin embargo, el nuevo proyecto educativo no opta por cerrar las heridas de la polarización y apuesta una vez más por la beligerancia religiosa, de resultados tan nefastos en el pasado.

\section{Referencias bibliográficas}

Bolívar Botia, A. (2015). The Comprehensive School in Spain: A Review of its Development Cycle and Crises. European Educational Research Journal, 14 (34), 347-363.

Díez de Velasco, F. (2016). La enseñanza de las religiones en la escuela en España: avatares del modelo de aula segregada. Historia y Memoria de la Educación, 4 (2), 277-306.

Escámez Sánchez, J., y Sanz Ponce, R. (2011). Los fines de la Educación Secundaria en la sociedad española actual. Edetania, 39 (1), 43-56.

García Pedraza, R. (2015). Desafíos a la igualdad en el siglo XXI: dificultades y retos del modelo de escuela comprensiva. Revista Española de Educación Comparada, 26 (2), 135-152.

Giner de los Ríos, F. (1927). Ensayos menores sobre educación y enseñanza (II). Madrid: Espasa-Calpe.

Giner de los Ríos, F. (1933). Estudios sobre educación. Madrid: Espasa-Calpe. Jiménez García, A. (1985). El krausismo y la Institución Libre de Enseñanza. Madrid: Cincel. 
Ministerio de Educación y Formación Profesional (MEFP) (2019a). LOMLOE. Nuevos cambios educativos. Educación de calidad con equidad. Disponible en https://bit.ly/2SECNW1

Ministerio de Educación y Formación Profesional (2019b). Proyecto de Ley Orgánica por la que se modifica la Ley Orgánica 2/2006, de 3 de Mayo, de Educación. Disponible en https://bit.ly/3deXpxg

Molero Pintado, A. (2000). La Institución Libre de Enseñanza. Un proyecto de reforma pedagógica. Madrid: Biblioteca Nueva.

Puelles Benítez, M. de (2010). Política y educación en la España contemporánea. Madrid: UNED.

Puelles Benítez, M. de (2011). La educación secundaria en la España democrática: antecedentes, problemas y perspectivas. Cadernos de Pesquisa, 144 (3), 710-731.

Turín, Y. (1967). La educación y la escuela en España de 1874 a 1902: liberalismo y tradición. Madrid: Aguilar.

Viñao Frago, A. (1982). Política y educación en los orígenes de la España contemporánea. Examen especial de sus relaciones en la enseñanza secundaria. Madrid: Siglo XXI. 